\title{
DE DEAF SENTENCE A SURDO MUNDO: O ELOQUENTE DIÁLOGO DE SURDOS ENTRE ORIGINAL E TRADUÇÃO NO ROMANCE DE DAVID LODGE
}

\section{Guilherme da Silva Braga}

No romance Deaf Sentence, David Lodge narra a história do professor universitário de linguística Desmond Bates, que aos poucos está perdendo a audição. Na tentativa de ocultar o problema, Desmond eventualmente tece comentários e responde a perguntas mesmo sem ter entendido o que os outros estão falando - e é assim que, inadvertidamente, aceita o convite da estudante de mestrado Alex Loom para ajudá-la a escrever uma dissertação sobre análise estilística de bilhetes de suicidas.

A partir do envolvimento entre o professor e a aluna, a narrativa passa a orientarse em função de um tema explicitado e de outro sugerido no título original: a surdez e a morte. O jogo linguístico evidenciado no trocadilho que serve de título ao livro - Deaf Sentence - apresenta-se como um desafio tradutório em miniatura, porém o maior desafio na tradução do romance é justamente o número de vezes e a variedade de contextos em que o protagonista Desmond Bates (um personagem com formação em linguística, fonologia e literatura que demonstra uma intimidade admirável com o mundo das palavras) entrega-se a reflexões e devaneios sobre a surdez e a morte - e muitas vezes por aquilo que imagina ser não apenas uma quase identidade sonora, mas também semântica entre deaf e death.

Os principais desafios durante a tradução de Deaf Sentence foram portanto os seguintes:

- trocadilho recorrente entre death e deaf;

- citações intencionalmente errôneas de obras e títulos de obras clássicas e modernas envolvendo o trocadilho entre death e deaf;

- outros trocadilhos e mal-entendidos fonéticos contextualizados;

- citações de frases feitas, títulos de músicas e poemas que versam sobre ouvidos e audição;

- trechos com descrições fonológicas da língua de origem;

- homofemas; 
- quebra-cabeças linguísticos;

- homofemas contextualizados;

- explicitação do recurso ao trocadilho entre death e deaf.

A primeira decisão tomada - como de praxe em minha prática tradutória consistiu em renunciar de antemão a escrever notas de tradutor que oferecessem explicações sobre os trocadilhos ou os declarassem "intraduzíveis", uma vez que essas notas privariam a obra traduzida de todas as evidentes características estilísticas e literárias do original para inseri-la no reino do mero comentário acadêmico. A mesma decisão também produziu o efeito desejado de obrigar-me a encontrar para o meu texto em português soluções tradutórias que fossem propriamente literárias e funcionassem de acordo com os mesmos princípios lúdicos e criativos que regem o original inglês.

A tradução resultante sem dúvida beneficiou-se da sistematização útil, ponderada e lúcida apresentada na teoria do escopo de Reiss e Vermeer - mas, embora eu esteja convicto de que as soluções adotadas poderiam ser integralmente justificadas com recurso a essa teoria, minha tradução não teve o objetivo declarado de encaixar-se nesta ou em qualquer outra corrente de pensamento sobre a tradução. Busquei apenas traduzir de maneira a apresentar ao leitor brasileiro uma tradução de Deaf Sentence em que o texto da obra se revelasse da maneira como o percebi - como um exercício de estilo que recorre a inúmeros trocadilhos e jogos linguísticos para dar andamento à narrativa. Este objetivo me deu a licença necessária para adotar soluções que não precisariam necessariamente traduzir o texto de Lodge no sentido estrito e limitado do termo (leia-se: traduzir o mero sentido), mas que me permitiriam manipular o texto em português brasileiro de maneira a imitar o processo criativo do autor e do personagem Desmond Bates para chegar a uma tradução equivalente no sentido em que esse termo adquire na teoria do escopo - ou seja, para chegar a uma tradução que faz no idioma de chegada aquilo que o original $\mathrm{faz}$ no idioma de partida.

Um dos métodos que se mostrou útil ao longo de toda a tradução foi determinar se, nos diferentes contextos em que trocadilhos ou jogos linguísticos surgem na obra, havia quaisquer elementos que justificassem a necessidade de uma tradução tout court de ambos os termos em que se baseavam. Como em diversas ocasiões Desmond faz interpretações equivocadas das palavras ditas por outros personagens, o procedimento serviu logo de início para separar os trechos em que seria necessário manter não apenas a semelhança fonológica, mas também uma aproximação semântica entre os termos - 
como por exemplo os casos em que Desmond toma duas palavras com semelhanças fonológicas e a partir destas estabelece também uma semelhança em termos do sentido — daqueles que, em função das interpretações completamente errôneas de Desmond, eu poderia traduzir com base no sentido apenas a frase de fato para então simplesmente ignorar o mal-entendido apresentado no original e, a partir do som presente na versão em português do trecho traduzido com base no sentido, recriar um outro mal-entendido qualquer. Esse pequeno descolamento em relação à superfície do texto original permitiu uma aproximação importante em termos um pouco mais abstratos: ficou assim estabelecido que, se a interpretação de Desmond era um equívoco motivado pela sonoridade da frase em inglês, bastaria que fosse também um equívoco motivado pela sonoridade da frase em português — não importando assim a carga semântica do equívoco. Sempre que possível tentei buscar no texto do original ideias que pudessem ser aproveitadas na tradução, mas na falta destas resolvi fazer o que poderia ser descrito como uma reescritura ou recriação do texto original. No entanto, cabe ressaltar que, em vista das características formais de Deaf Sentence, nesse contexto os termos "reescritura", "recriação" e "tradução" podem ser entendidos como sinônimos — e o principal objetivo deste artigo é justamente demonstrar como essa mudança de perspectiva pode resultar em traduções que, por força da verossimilhança e da coerência interna, deem uma impressão geral de extrema proximidade com o original em relação às características estilísticas e literárias da obra como um todo, mesmo quando, nas camadas superficiais da simples palavra e da simples frase, distanciam-se consideravelmente do original.

A primeira cena de Deaf Sentence fornece um exemplo simples mas bastante ilustrativo da maneira como o texto original se articula: ${ }^{1}$

For the man now almost nuzzling the bosom of the woman in the red blouse, as he brings his right ear closer to her mouth, the noise reached some time ago a level that makes it impossible for him to hear more than the odd word or phrase of those she addresses to him. 'Side' seems to be one recurring word-or is it 'cider'? And 'flight from hell' - or was it 'cry for help'? He is, you see, 'hard of

1 Ao longo de todo o artigo, utilizo negritos para destacar os trechos do texto original de David Lodge e da minha tradução que servem como ponto de partida para as reflexões apresentadas. Os destaques não se encontram nos textos originais. 
hearing', or 'hearing impaired' or, not to put too fine a point on it, deaf - not profoundly deaf, but deaf enough to make communication imperfect in most social situations and impossible in some, such as this one.

Baseado na premissa apresentada anteriormente, segundo a qual os malentendidos de motivação fonológica seriam traduzidos por mal-entendidos de motivação fonológica que podiam ou não coincidir em termos de sentido com o original, traduzi as palavras side e o sintagma cry for help por "lado" e "pedido de ajuda" para chegar à solução a seguir, tomando o cuidado de escolher sempre palavras ou sintagmas que soassem plausíveis no contexto em que aparecem no original - no caso em questão, conversas entre desconhecidos em uma vernissage:

O homem quase enfia o nariz entre os seios da mulher com a blusa vermelha ao levar a orelha direita para junto dos lábios dela, pois há algum tempo o barulho atingiu um nível que o impossibilita de entender mais do que uma ou outra palavra do que ela diz. "Lado" parece ser uma palavra recorrente - ou seria "dado"? E seria "perdido na rua" ou "pedido de ajuda"? Como você pode ver, ele é "duro de ouvido", ou, dito de maneira simples, surdo - não completamente surdo, mas surdo o bastante para tornar a comunicação difícil em muitas ocasiões sociais e impossíveis em outras, como esta.

Na volta para casa, Desmond conversa com a esposa Fred sobre o evento:

'You were deep in conversation with a young blonde.'

'I didn't see Ron. Was he there?'

'Not Ron. The blonde woman you were talking to, who was she?'

'Oh. I've no idea. She told me her name, twice in fact, but I couldn't make it out.

I didn't hear a word she was saying. The noise ... '

'It's all the concrete.'

'There's nothing wrong with the heating, in fact it's always too bloody hot for my liking.'

'No, concrete. The walls, the floor. It makes the sound reverberate.'

'Oh...'(Pause.)

'What did you think of the exhibition?'

'I thought she might be one of your customers.'

'Who?'

'The young blonde woman.'

'Oh. No, I've never seen her before. What did you think of the exhibition?'

'What?'

'The exhibition - what did you think?'

'Drab, boring. Anyone with a digital camera could take those pictures.'

'I thought they had a kind of interesting . . sadness.'

'Can badness be interesting?'

'Sadness, an interesting sadness. Are you wearing your hearing' aid, darling?' 
Ron, mencionado logo no início do diálogo, é um personagem totalmente secundário para a trama. Além do mais, o fato de que não estava presente na festa como o próprio Desmond parece intuir ao contrário do que imagina ter escutado, quando pergunta "Was he there?" - permite ao leitor concluir que essa é apenas mais uma interpretação equivocada do que foi dito, e a correção de Fred - "Not Ron. The blonde..." - reforça o equívoco. Por outro lado, a palavra blonde descreve Alex Loom, personagem central na trama da história, o que limita a margem de negociação do tradutor em relação a uma descrição física dessa personagem. O trecho foi resolvido com uma tradução convencional de blonde por "loira" e com a postulação de uma personagem adicional chamada "Moira" que, por não figurar na trama (uma vez que não estava na festa, assim como Ron tampouco estava no original), não traz modificação alguma à história — um arranjo simples que permite preservar o aspecto formal essencial do trecho: a plausibilidade e os efeitos produzidos pela surdez de Desmond.

O mal-entendido entre heating e concrete é resolvido de maneira natural em português com a simples tradução dos termos por "aquecimento" e "cimento", enquanto o par formado por sadness e badness exige um tratamento um pouco mais criativo em cima do texto para se tornar plausível, como se pode ver a seguir:

"Você estava conversando com uma moça loira."

"Eu não vi Moira. Ela estava lá?"

"Não, Moira não. A moça loira que estava falando com você, quem era?"

"Ah. Não faço a menor ideia. Ela me disse o nome dela, duas vezes até, mas eu não consegui entender. Não entendi uma palavra do que ela disse. O barulho..." "É por causa do cimento."

"Por mim não precisa de aquecimento algum, você sabe que eu estou sempre morrendo de calor."

"Não, eu disse cimento. Nas paredes, no chão. Faz o som reverberar."

"Ah..." (Pausa.)

"O que você achou da exposição?"

"Achei que ela pudesse ser cliente sua."

"Quem?"

"A moça loira."

"Ah. Não, eu nunca vi ela antes. O que você achou da exposição?”

"O quê??"

"A exposição - o que você achou?"

"Chata, insossa. Qualquer um com uma câmera digital pode tirar fotos idênticas."

"Eu achei interessante aquele desalento..."

"O que tem de interessante em alguém sem talento?"

"Desalento, eu achei interessante o desalento. Você está usando o aparelho 
auditivo, querido?"

O sentido geral do trecho deixa-se reproduzir de maneira bastante próxima ao se traduzir sadness por "desalento", e um pouco de trabalho em cima do ritmo e da sonoridade das vogais na frase em português que resulta da tradução de "I thought they had a kind of interesting ... sadness" cria a possibilidade de se traduzir o retruque "Can badness be interesting?" por "O que tem de interessante em alguém sem talento?" uma escolha que em termos semânticos não se distancia muito do original, visto que a falta de talento é uma das razões a que se pode atribuir a ruindade ("badness") de uma obra de arte.

A seguir, Desmond começa uma das divagações filosóficas sobre a natureza da surdez e a maneira diametralmente oposta como - de acordo com o personagem - se relaciona à privação sensorial imposta pela cegueira:

Deafness is comic, as blindness is tragic. Take Oedipus, for instance: suppose, instead of putting out his eyes, he had punctured his eardrums. It would have been more logical actually, since it was through his ears that he learned the dreadful truth about his past, but it wouldn't have the same cathartic effect. It might arouse pity, perhaps, but not terror. Or Milton's Samson: 'O dark, dark, dark, amid the blaze of noon, I Irrecoverably dark, without all hope of day.' What a heartbreaking cry of despair! ' $O$ deaf, deaf, deaf. . .' doesn't have the same pathos somehow. How would it go on? 'O deaf, deaf, deaf, amid the noise of noon, / Irrecoverably deaf, without all hope of sound.' No.

O trecho faz uma citação explícita aos versos de Milton no poema Samson Agonistes. A dificuldade mais evidente diz em primeiro lugar respeito à métrica, uma vez que dark e deaf têm o mesmo número de sílabas em inglês - uma. A segunda diz respeito à tripla aliteração em $d$, presente tanto em "O dark, dark, dark" como no pastiche "O deaf, deaf, deaf". Sendo a referência à surdez o tema do livro por excelência, não pareceu possível nem desejável substituí-la por qualquer outra alusão, de maneira que o termo deaf foi traduzido por "surdo". Todo o poema original de Milton e o restante do pastiche foram pensados a partir da sonoridade e das metrificações possíveis com recurso a essa palavra, e o resultado foi o que se pode ler abaixo:

A surdez é cômica como a cegueira é trágica. Tomemos Édipo como exemplo: imagine que, em vez de furar os olhos, ele furasse os tímpanos. Na verdade faria bem mais sentido, já que foi através dos ouvidos que ele descobriu a terrivel verdade enterrada em seu passado, mas o efeito catártico não seria o mesmo. Talvez despertasse 
compaixão, mas não terror. Ou então o Sansão de Milton: "Escuro, escuro, em meio ao sol diurno, / Escuro eterno, eclipse total / para o qual não há manhã.” Que desespero plangente! "Sou surdo, surdo..." não tem o mesmo páthos. Como haveria de continuar? "Sou surdo, surdo, em meio ao som diurno, / Sou um surdo eterno, um mouco total / para o qual não há barulho.” Não, não.

A tripla repetição de deaf e dark deu vez a uma repetição dupla, e a aliteração em $d$ transformou-se em uma assonância em $u$ em português; a assonância dos termos monossilábicos blaze e noise deixa-se traduzir pela aliteração também monossilábica entre "sol" e "som" - este último um termo que, que na solução adotada, traduz noise, o que provocou o deslocamento do termo "barulho" para o último verso do pastiche na tradução.

Dando continuidade a essas divagações, Desmond continua a discutir expressões idiomáticas e um poema de Ben Jonson ("Song to Celia") que fazem menção aos olhos e tenta mostrar como perderiam força caso se referissem às orelhas:

Of course, you could argue that blindness is a greater affliction than deafness. If I had to choose between them, I'd go for deafness, I admit. But they don't differ only in degrees of sensory deprivation. Culturally, symbolically, they're antithetical. Tragic versus comic. Poetic versus prosaic. Sublime versus ridiculous. One of the strongest curses in the English language is 'Damn your eyes!' (much stronger than 'Fuck you!' and infinitely more satisfying - try it next time some lout in a white van nearly runs you over). 'Damn your ears!' doesn't cut it. Or imagine if the poet had written 'Drink to me only with thine ears ...' It's actually no more illogical than saying drink with thine eyes. Both metaphors are equally impossible concepts, in fact an ear is more like a cup than an eye, and you could conceivably drink, or at least slurp, out of an ear, though not your own of course . . But poetical it isn't. Nor would 'Smoke gets in your ears' be a very catchy refrain for a song. If smoke gets in your eyes when a lovely flame dies it must get in your ears too, but you don't notice and it doesn't make you cry. "There's more in this than meets the ear' is something Inspector Clouseau might say, not Poirot.

Dada a escassez de qualquer imprecação em português que faça menção aos olhos, busquei para minha tradução uma outra expressão idiomática que os mencionasse e por fim me decidi por "vi com estes olhos que a terra há de comer", o que me exigiu ajustes no comentário feito entre parênteses pelo personagem. Logo a seguir, o clássico poema de Ben Jonson - creditado no trecho apenas como "the poet" - foi traduzido de maneira bastante ortodoxa, embora na tradução o poeta apareça creditado pelo nome de maneira a marcar para o leitor brasileiro a existência de mais um pastiche, enquanto o refrão "Smoke gets in your ears", que faz um pastiche de "Smoke gets in your eyes", simplesmente não foi traduzido por tratar-se de uma letra de música. O bordão de Poirot, no entanto, apresenta uma dificuldade inesperada de tradução: uma consulta às 
obras de Agatha Christie revela que o bordão do inspetor foi traduzido de diferentes maneiras em diferentes obras, com o resultado de que não há, em nosso idioma, nenhum bordão facilmente atribuível ao personagem. A solução adotada visou recriar esse efeito de familiaridade e optou por um lugar-comum da fala cotidiana, que não faz referência a nenhuma obra e a nenhum personagem em particular:

Claro, pode-se argumentar que a cegueira é mais grave que a surdez. Se eu tivesse de escolher entre as duas coisas, reconheço que eu ficaria com a surdez. Mas as duas não se distinguem apenas no grau de privação sensorial. Em termos culturais e simbólicos, a cegueira e a surdez são antíteses. Trágico versus cômico. Poético versus prosaico. Sublime versus ridículo. Uma das expressões mais fortes para afirmar alguma coisa é "vi com estes olhos que a terra há de comer" (muito mais contundente do que "juro que vi" - experimente na próxima vez que algum chato duvidar de você). "Ouvi com estes ouvidos que a terra há de comer" simplesmente não dá certo. Ou imagine se Ben Jonson tivesse escrito "Beba para mim só com as tuas orelhas"... Na verdade não seria menos lógico do que escrever "Beba para mim só com os teus olhos", como o poeta fez. As duas metáforas são conceitos igualmente impossíveis, e na verdade uma orelha é bem mais parecida com uma taça do que um olho, e em teoria é possivel beber, ou ao menos chupar o líquido de uma orelha, desde que não seja a sua própria... Mas não é nada poético. "Smoke gets in your ears" também não daria um bom refrão. Se a fumaça entra nos seus olhos quando uma chama se apaga, ela deve entrar nos seus ouvidos também, mas você nem percebe e isso não faz você chorar. "Estou de ouvido em vocêe" não tem o mesmo impacto da contrapartida visual.

Mais adiante, em outra referência poética, Desmond cita um trecho de "A Tale of a Trumpet", de Thomas Hood:

Of all old women hard of hearing

The deafest, sure was Dame Eleanor Spearing!

On her head, it is true

Two flaps there grew

That served for a pair of gold rings to go through,

But for any purpose of ears in a parley,

They heard no more than ears of barley.

Ao contrário do que se observa em quase todos os trechos citados até aqui, essa é uma citação direta sem nenhum tipo de manipulação: trata-se apenas do texto de Hood, sem quaisquer modificações introduzidas por Desmond. Minha primeira decisão tradutória foi manter as rimas e a métrica do original na tradução para o português mas qualquer solução teria necessariamente de resolver a dificuldade suscitada pelo 
trocadilho entre ear ("orelha") e ear ("espiga"). Mais uma vez, tomei a orelha como ponto de partida em função da alusão à surdez (absolutamente explícita no original) e comecei a buscar objetos inanimados que em português tivessem orelhas, o que me levou ao seguinte resultado:

\author{
De todas as velhas duras de ouvido, \\ Igual a Eleanor Spearing não terá havido! \\ Em sua cabeça, nos lados \\ Enxertos grudados \\ Davam abrigo a dois brincos dourados, \\ Mas aquelas orelhas, na trela com amigos, \\ Ouviam não mais que as dos livros antigos.
}

Ao oferecer detalhes sobre o tipo particular de surdez que o aflige, Desmond faz uma menção ao texto inglês de Alice in Wonderland e evidencia familiaridade com a disciplina de fonologia:

I could hear vowels perfectly well - still can. But its consonants that we mainly depend on to distinguish one word from another. "Did you say pig or fig?" said the Cat. "I said pig," replied Alice.' Maybe the Cheshire Cat was a bit deaf: it wasn't sure whether Alice had used a bi-labial plosive or a labiodental fricative the first time she pronounced the word, and being a well-brought-up Victorian middle-class little girl she would have spoken very clearly. ' $\boldsymbol{F}$ ' is called a labiodental fricative because you produce it by bringing your front teeth into contact with your bottom lip and allowing some air to escape between them. It's also called a continuant because you car continue making the sound as long as you have breath fffffffffffffffffffffff. . . though I can't imagine why you would want to unless perhaps you started to say 'Fuck' and thought better of it. I have a smattering of phonetics, although it's not my field.

$\mathrm{Na}$ tradução deste trecho, a descrição fonética teria necessariamente de corresponder ao fonema responsável pela confusão do Gato de Cheshire na tradução para o português, de maneira que o primeiro passo foi determinar qual seria a tradução adotada para a pergunta "Did you say pig or fig?". Depois de consultar o original e constatar que de fato há um porco nesta cena, recorri a algumas das traduções do livro para o português brasileiro e concluí que a melhor solução seria traduzir a pergunta como "Você disse porco ou porto?" - o que naturalmente pediria uma descrição fonológica de /t/, que em português seria o fonema causador do mal-entendido. Esta solução entra em conflito com o trecho logo a seguir, uma vez que o som de $f$ (completamente ausente em "porco" e "porto") é necessário para possibilitar a tradução 
de "Fuck" por "foda-se", porém uma simples comparação fonológica entre /f/ e /t/ — tornada plausível graças ao comentário explícito do personagem quando diz "I have a smattering of phonetics" - e o emprego de uma negativa tornam possível uma solução bastante eficiente do trecho como um todo:

\begin{abstract}
Eu podia - e ainda posso - ouvir perfeitamente as vogais. Mas é das consoantes que dependemos para distinguir as palavras umas das outras. "Você disse porco ou porto?”, perguntou o Gato. “Eu disse porco”, respondeu Alice. Talvez o Gato de Cheshire fosse um pouco surdo: ele não tinha certeza se Alice tinha usado uma oclusiva velar ou uma oclusiva linguodental na primeira vez em que Alice pronunciou a palavra, mas, sendo uma garotinha muito bem-educada da classe média vitoriana, sem dúvida ela falou com uma dicção claríssima. 'T' é uma consoante linguodental porque, para produzir o som que ela representa, você encosta a língua na parte posterior dos dentes frontais, o que bloqueia completamente a passagem do ar. Daí a classificação "oclusiva": você não pode prolongar um $t$ da mesma maneira que pode prolongar um fffffffffffffffffffffff, embora eu não consiga imaginar o que levaria alguém a fazer uma coisa dessas (a não ser que você começasse a dizer "foda-se" $e$ depois mudasse de ideia). Eu entendo um pouco de fonética, embora não seja a minha área.
\end{abstract}

Uma das passagens de solução mais complexa e trabalhosa em todo o romance diz respeito ao momento em que Desmond, após relatar a equivocada "descoberta" de um livro de autoajuda para os surdos e duros de ouvido que na verdade não passava de mais um mal-entendido, põe-se a tecer comentários sobre a semelhança não apenas fonológica, mas também semântica, entre os adjetivos deaf e dead. Como já havia feito antes, o personagem lança mão de referências poéticas, embora desta vez não as manipule apenas para mostrar que eventuais pastiches soariam ridículos ou absurdos, mas justamente para que sirvam de mote a comentários repletos de sentido sobre a natureza da surdez. Diz o original:

I was at a party a few years ago, not as noisy as the one last night but bad enough, and I overheard a man enthusing about a book he was reading called Being Deaf. It sounded like just the book for me: a self-help manual I presumed, but I didn't like to barge into the conversation demanding the bibliographical details. The man was talking to a girl who was looking admiringly into his eyes and nodding eager agreement, and he left the party early (with the girl) before I had an opportunity to speak to him. So the next day I went to Waterstone's to try and get the book. 'What was the author's name?' the assistant asked. 'I think it was Grace,' I said. It turned out to be Grace, Jim Grace, and the book was a novel called Being Dead. Often only the context allows me to distinguish between 'deaf' and 'death' or 'dead', and sometimes the words seem 
interchangeable. Deafness is a kind of pre-death, a drawn-out introduction to the long silence into which we will all eventually lapse. 'To every man upon this earth, / Deaf cometh soon or late', Macaulay might have written. But not Dylan Thomas, 'After the first deaf, there is no other'. There are lots of others, stages of auricular decay, like a long staircase leading down into the grave.

O livro Being Dead, de Jim Grace, efetivamente existe, porém nunca foi traduzido para o português - e, ainda que tivesse sido lançado no Brasil, o título em nosso país dificilmente se prestaria a qualquer trocadilho que fizesse sentido no contexto da história de Deaf Sentence. A solução do trecho como um todo dependia do emprego de um recurso idêntico àquele observado no original - o emprego de palavras ou sintagmas que não fossem semelhantes apenas no plano fonológico, mas também se prestassem ao mesmo tipo de comentário em relação à morte e à surdez. Cheguei a uma solução interessante ao traduzir deaf por "má audição" e death por "maldição":

Uns anos atrás eu estava em uma festa, não tão barulhenta quanto a da noite passada, mas ainda assim barulhenta, e escutei um homem falar entusiasmado sobre um livro que ele estava lendo, chamado A má audição em família. Parecia o livro ideal para mim: uma espécie de manual de autoajuda, imaginei, mas não quis me intrometer na conversa para pedir os detalhes bibliográficos. O homem estava conversando com uma garota que olhava fundo nos olhos dele, cheia de admiração, ao mesmo tempo em que acenava sem parar com a cabeça, e acabou indo embora (com a garota) antes que eu pudesse abordá-lo. No dia seguinte fui até a Waterstone's para ver se eu encontrava o livro. "O senhor sabe quem é o autor?" "Acho que é Daniel”, respondi. Na verdade era Dashiel, Dashiel Hammett, e o livro era um romance policial chamado Maldição em família. Muitas vezes só o contexto permite que eu distinga "má audição" de "maldição", e em outras as palavras parecem intercambiáveis. A má audição não deixa de ser uma espécie de maldição, uma maldição que precede o longo silêncio onde todos nós por fim acabaremos. "A todo homem nesta terra, / A má audição da morte alcança”, poderia ter escrito Macaulay. Mas Dylan Thomas não teria escrito que "Depois da primeira surdez, não há outra”. Há muitas outras - estágios da deterioração auditiva que, como uma longa escadaria, descem até as profundezas do túmulo.

Como se pode observar na tradução acima, a solução adotada permitiu-me não apenas reformular os comentários feitos por Desmond de maneira plausível, mas também começar uma pesquisa sobre títulos de livros lançados no Brasil que contivessem a palavra "maldição" e pudessem dar a impressão de ser uma obra de autoajuda para pessoas com deficiências auditivas quando esse termo fosse substituído por "má audição" - e por fim encontrar o romance de Dashiel Hammett publicado no Brasil com o título Maldição em família, que atendia a todas essas exigências. O mesmo 
recurso também me permitiu traduzir o pastiche de Macaulay sem grandes afastamentos semânticos em relação ao pastiche original. No que diz respeito ao poema de Thomas, a solução adotada foi diferente, pois o problema era um pouco mais complexo: a tradução "Depois da primeira má audição, não há outra" resultaria em um texto implausível, que postularia a existência de um original traduzido que dissesse "Depois da primeira maldição, não há outra" como uma tradução poética válida do original em inglês "After the first death, there is no other". Assim, me pareceu melhor simplesmente traduzir o verso de maneira literal e confiar ao leitor a tarefa de perceber que, em vista da dupla referência à morte e à surdez feita imediatamente antes no poema de Macaulay, trata-se aqui da mesma coisa, com a diferença de que um dos elementos de sentido encontra-se ausente.

Outro mal-entendido contextualizado surge quando Desmond e Fred ensejam uma conversa sobre o noticiário na televisão:

....Fred reclined on the sofa with her feet up, watching Newsnight on television, and I caught a glimpse of soldiers in battledress patrolling a dusty Middle Eastern street before she quenched the picture with the remote. I went over to the sofa and she tilted her face to receive a kiss.

'Carry on watching if you want to,' I said.

'No, darling, it's too depressing. Another suicide bomb in Baghdad.'

I sank down in an armchair, and took off my shoes. Fred said something I didn't catch, I presumed about the news, something about a mine.

'How could you commit suicide with a mine?' I asked. I saw from her expression that this was wrong. 'Hang on,' I said, and fumbled in my pocket for my hearing aid, which I had taken out in the train. As I inserted the earpieces I discovered that one of them was already switched on. 'What did you say?'

'I said you're whining, darling. Or you were.'

'I must have forgotten to turn one of these things off. Either that or it turned itself on somehow. I suspect them of doing that occasionally.'

'So how was your Awayday?' Her tone was sympathetic, but the microhumiliation of the whining hearing aid, reminder of my infirmity, lingered like the irritation of an insect bite, and diminished the pleasure of my homecoming. Deaf, where is thy sting? Answer: everywhere.

No contexto ficcional, a notícia diz respeito a um atentado suicida, mas o problema auditivo de Desmond leva-o a crer que a esposa teria dito qualquer coisa a respeito de uma mine ("mina terrestre”), embora o personagem logo perceba que não é esse o caso: a esposa dizia apenas que o aparelho auditivo do marido estava whining. A solução adotada partiu de uma do termo por "zumbindo", e a partir de então — baseado mais uma vez na premissa de que a compreensão de Desmond estava equivocada, e que 
portanto qualquer compreensão equivocada com motivação sonora poderia servir como solução ao trecho - a menção atrapalhada à mina terrestre foi substituída por uma menção ainda mais descabida a um "bingo", enquanto a citação bíblica ao final do trecho teve a palavra "morte" substituída por surdez, deixando ao leitor a tarefa de reconstruir o raciocínio feito por Desmond - exatamente como aconteceu no trecho imediatamente anterior em relação ao poema de Dylan Thomas:

Fred estava deitada no sofá com os pés para cima, assistindo Newsnight na televisão, e de relance eu vi soldados fardados fazendo a patrulha de uma rua poeirenta no Oriente Médio antes que ela apagasse a imagem com o controle remoto. Fui até o sofá e ela inclinou o rosto para receber um beijo.

"Pode continuar assistindo, se você quiser", eu disse.

"Não, querido, é muito deprimente. Mais um homem-bomba em Bagdá." Afundei em uma poltrona e tirei os sapatos. Fred disse algo que eu não entendi, acho que sobre o noticiário, alguma coisa sobre "bingo".

"Mas o que o bingo tem a ver com o homem-bomba?", perguntei. Vi pela expressão dela que algo estava errado. "Só um pouco", eu disse, e remexi o meu bolso em busca dos aparelhos auditivos, que eu havia tirado no trem. Ao colocálos, percebi que um deles já estava ligado. "O que você disse?"

"Eu disse que você está zumbindo, querido. Ou melhor, estava."

"Eu devo ter esquecido de desligar essas coisas. Ou então elas se ligaram sozinhas. Acho que às vezes elas fazem isso."

"Como foi o seu dia longe de casa?" O tom de voz dela era agradável, mas a micro-humilhação do aparelho auditivo zumbidor, símbolo da minha debilidade, perdurou como a irritação de uma picada de inseto e diminuiu o prazer do meu retorno ao lar.

Onde está, surdez, o teu aguilhão? Resposta: em toda parte.

O método de primeiro traduzir o sentido do contexto efetivo na situação ficcional para então adaptar a suposição equivocada do protagonista com base em critérios sonoros e, a partir daí, ajustar quaisquer comentários feitos a respeito desta mesma suposição equivocada a fim de conferir-lhes plausibilidade serviu também para resolver o seguinte trecho:

I got up this morning before Fred and was having my breakfast when she came into the kitchen in her dressing gown. She said 'Good morning, darling,' and then, going over to the stove, said something else which I didn't catch because I wasn't wearing my hearing aid; I took it out last night in the family bathroom, which is my bathroom when there are no family or other guests in the house, before going to bed, and it was still there. I said 'What?' and she repeated the utterance, but I still didn't get it. She was opening and shutting drawers and cupboards as she spoke, which didn't help. 'Sorry,' I said, 'I haven't got my hearing aid in - it's upstairs.' She turned to face me and said more loudly what 
sounded like 'long stick'. I said, 'What do you want a long stick for?' My mind was already considering the possibilities - to recover something that had rolled under the bed? Or fallen down the back of a chest of drawers? She came closer and said, 'Saucepan. Long-stick saucepan.' 'What's a long-stick saucepan?' I said. 'You mean a long-handled saucepan?' She raised her eyes to the heavens in despair, and went back to the stove. I thought about it for a minute or two, and then the penny dropped. 'Oh, you mean non-stick saucepan! It's in the top righthand cupboard.' But I was too late: she was already making her porridge in a stainless steel saucepan which would be much more trouble to clean afterwards. And it was my fault for putting the non-stick one away yesterday in the wrong place.

Hoje eu levantei antes de Fred e estava tomando café da manhã quando ela entrou na cozinha ainda de camisola. Ela disse "Bom dia, querido" e então, indo em direção ao fogão, disse mais alguma coisa que eu não captei porque não estava usando o aparelho auditivo; ontem à noite, antes de me deitar, eu o havia tirado no banheiro da família, que é o meu banheiro quando não temos família nem outros convidados em casa, e ele ainda estava lá. Eu disse "O quê?" e ela repetiu a frase, mas continuei sem entender. Ela estava abrindo $e$ fechando cortinas e armários enquanto falava, o que não ajudou muito. "Desculpe", eu disse, "mas eu não estou usando o aparelho - está lá em cima." Ela se virou na minha direção e disse, levantando a voz, algo que soou como “aguardente”. Eu perguntei, "Para que você quer aguardente?". Meu cérebro já estava considerando as possibilidades - alguma receita de sobremesa? Ou talvez um molho de carne? Ela chegou mais perto e disse, "Panela. Panela de aguardente." "O que é uma panela de aguardente?”, perguntei. "Você quer dizer uma garrafa?" Ela ergueu os olhos para o céu em desespero e voltou para o fogão. Fiquei pensando por mais alguns instantes e então a ficha caiu. "Ah, você está falando da panela antiaderente! Está no armário da direita." Mas eu demorei demais: ela já estava preparando o mingau em uma panela de inox que daria muito mais trabalho para limpar depois. E por minha culpa, porque eu tinha guardado a panela antiaderente no lugar errado.

Em um episódio posterior da narrativa surge um exemplo ainda mais extremo deste mesmo procedimento:

Then Sylvia Cooper, wife of the former Head of History, engaged me in one of those conversations in which your interlocutor says something that sounds like a quotation from a Dadaist poem, or one of Chomsky's impossible sentences, and you say 'What?' or 'I beg your pardon?' and they repeat their words, which make a banal sense the second time round.

'The pastime of the dance went to pot,' Sylvia Cooper seemed to say, 'so we spent most of the time in our shit, the cows' in-laws finding they stuttered.'

'What?' I said.

'I said, the last time we went to France it was so hot we spent most of the time in our gite, cowering indoors behind the shutters.'

'Oh, hot, was it?' I said. 'That must have been the summer of 2003.'

'Yes, we seared our arses on bits of plate, but soiled my cubism, I'm afraid.' 
'I'm sorry?'

'We were near Carcasonne. A pretty place, but spoiled by tourism, I'm afraid.'

'Ah, yes, it's the same everywhere these days,' I said sagely.

'But I do mend sherry. Crap and sargasso pained there, you know. There's a lovely little mum of modern tart.'

'Sherry?' I said hesitantly.

'Ceret, it's a little town in the foothills of the Pyrenees,' said Mrs Cooper with a certain impatience. 'Braque and Picasso painted there. I recommend it.'

'Oh yes, I've been there,' I said hastily. 'It has a rather nice art gallery.'

'The mum of modern tart.'

'Quite so,' I said.

Como se pode ler na citação acima, o próprio Desmond descreve a situação como "one of those conversations in which your interlocutor says something that sounds like a quotation from a Dadaist poem, or one of Chomsky's impossible sentences, and you say 'What?' or 'I beg your pardon?' and they repeat their words, which make a banal sense the second time round". Interpretei o trecho como uma instrução para traduzir primeiro o "sentido banal" do que Sylvia Cooper diz e, a partir do som das frases geradas pelas traduções, reescrever outras frases que "parecem citações de um poema dadaísta, ou uma das frases impossíveis de Chomsky". O resultado foi o que se lê a seguir:

Logo Sylvia Cooper, esposa do ex-diretor do setor de História, teve comigo uma daquelas conversas em que o seu interlocutor diz coisas que parecem citações de um poema dadaísta, ou uma das frases impossíveis de Chomsky, e você pergunta "O quê?" ou "Como?" e então eles repetem as palavras, que na segunda vez fazem um sentido banal.

"A última vez que estivemos na dança estava tão rente", Sylvia Cooper pareceu dizer, "que caçamos a maior parte do vento na banana, bem mordidos e com as bobinas meladas."

"O quê?", perguntei.

"A última vez que estivemos na França estava tão quente que passamos a maior parte do tempo na cabana, encolhidos e com as cortinas fechadas."

"Ah, estava quente, é?", disse eu.

"Deve ter sido no verão de 2003."

"A lêndea estava em pé no megafone. Ulular é um ruído, mas traz gado pelo cubismo."

"Como?"

"A gente estava perto de Carcassone. O lugar é bonito, mas estragado pelo turismo."

"Ah, mas hoje em dia é assim em toda parte", comentei, cheio de sabedoria.

"Bateu remoendo um CD. Traque e apitaço piscaram por lá, sabia? Tem um belo museu de ar de moela."

“CD?” repeti, hesitante.

“Céret, é uma cidadezinha no pé dos Pireneus”, disse a sra. Cooper com certa impaciência. Braque e Picasso pintaram por lá. Eu recomendo.” 
"Ah, claro, eu já estive lá", apressei-me em dizer.

"Tem uma bela galeria de arte."

"O museu de ar de moela."

"Isso mesmo", eu disse.

Em outra cena, Desmond lamenta o ocorrido na cena inicial do livro - o malentendido que o levou a inadvertidamente ter contato com Alex, o que resultou mais tarde em um relacionamento estranho e ambíguo entre o ex-professor acadêmico e a atraente aluna de mestrado. Ao cogitar as desculpas que poderia oferecer à esposa para ocultar uma visita ao apartamento de Alex, Desmond faz uma referência trocadilhesca a um tema clássico da arte europeia: a morte e a donzela, death and the maiden. A palavra death, no entanto - como via de regra acontece no livro — é substituída por deaf:

I mentioned to Fred at breakfast, as casually as I could manage, that I was meeting Alex at the University this afternoon to give her some tips about her research, though in fact I had agreed to go to her apartment again. My plan was to tell Fred this evening that Alex had phoned later in the morning and asked me to come to her flat instead of the University because she had to be at home to receive a delivery. . . Then I could describe the flat to Fred as if I had seen it today for the first time, and there would be no need for further subterfuge about my relationship with Alex in the future. Now I desperately wish that it had no future. If only I had heard what she was saying when we first met it would never have started. Deaf and the maiden, a dangerous combination.

Nesse trecho parti da tradução cristalizada "a morte e a donzela" para buscar uma solução de sonoridade plausível que também se encaixasse de maneira adequada no contexto ficcional - porém desta vez abrindo mão da referência explícita à surdez (que a essa altura da narrativa já se encontra suficientemente clara para o leitor) para atribuir o ocorrido não diretamente aos problemas auditivos em si, mas ao infortúnio de sofrer as consequências que trazem. A tradução do trecho "If only I had heard what she was saying" por "Se eu não tivesse dado o azar de não escutar o que ela me disse" serviu para fazer essa transição, e assim o termo deaf foi traduzido por "má sorte", que se encaixa no contexto ficcional da tradução e também se aproxima da sonoridade de "morte":

Enquanto tomávamos o café da manhã, mencionei a Fred da forma mais casual possível que à tarde eu encontraria Alex Loom na universidade para lhe dar alguns conselhos sobre a pesquisa, embora na verdade eu tivesse me comprometido a ir ao apartamento dela outra vez. O meu plano era contar a Fred que Alex tinha me ligado mais tarde pela manhã e pedido que nos 
encontrássemos no apartamento dela em vez de na universidade porque ela estava à espera de uma encomenda. Fred poderia ficar meio desconfiada, mas eu daria um jeito de me explicar, dizendo por exemplo que eu sempre tinha sentido curiosidade de ver um daqueles prédios perto do canal por dentro. Assim eu poderia descrever o apartamento para Fred como se eu o tivesse visto hoje pela primeira vez, e daí em diante não haveria mais necessidade de esconder nada a respeito de Alex no futuro. Mas neste instante o que eu mais queria é que Alex não estivesse no meu futuro. Se eu não tivesse dado o azar de não escutar o que ela me disse quando nos encontramos pela primeira vez, sequer teríamos nos envolvido. A má sorte e a donzela, uma combinação perigosa.

Por insistência da esposa, a certa altura da narrativa Desmond passa a frequentar aulas de leitura labial em grupo na tentativa de compensar, com o sentido da visão, a perda de entendimento ocasionada pela audição insuficiente. Nesse ponto o personagem apresenta ao leitor o conceito de homofema, e no mesmo fôlego explica uma atividade proposta aos alunos do grupo de leitura labial e a maneira lúdica como encara a tarefa:

We had an exercise in small groups involving homophenes - the deafie's equivalent to homophones, words which look alike on the lips but have a different meaning, like mark, park and bark, or white, right and quite, rewire and require. We had to make up sentences using one of these words and lipspeak them to the group. I made up a sentence using all the words in two sets,'Quite right, the white room requires rewiring,' which of course nobody could lip-read, and there was much protesting laughter when they gave up and I said it with voice.

Nesse trecho, as palavras listadas como exemplos de homofemas foram simplesmente ignoradas na tradução — apenas busquei quaisquer homofemas em português que me permitissem reescrever uma frase indecifrável para um interlocutor que dependesse da prática de leitura labial para acompanhar o que está sendo dito:

Fizemos um exercício em grupo sobre homofemas, que para os surdos são como os homófonos: palavras que se formam de maneira idêntica nos lábios, mas têm significados diferentes, como mar, par e bar ou feio e veio e bote e bode. Tínhamos de criar frases usando uma dessas palavras e dizê-las sem usar a voz para a turma. Criei uma frase usando todas palavras desses três conjuntos: “Um par de bodes feios veio num bote pelo mar". Ninguém conseguiu decifrála, é claro, e houve muitos protestos e risadas quando todos desistiram e eu repeti a frase em voz alta.

Imediatamente a seguir, uma outra atividade — já não mais relacionada à leitura labial em si - é apresentada aos participantes do grupo: trata-se de um jogo chamado 
"Animal Crackers", e Desmond descreve com bom humor a derrota sofrida, encarada como um bem-humorado "castigo" pela brincadeira feita com os colegas na atividade anterior:

I was justly punished for showing off in this fashion by the next exercise, a quiz, to be completed in pairs, called Animal Crackers, which was a list of words with letters missing which themselves spelled out the name of an animal. Thus the solution to Ball - - - ing was Ballbearing, Bl - - $\boldsymbol{t}$ - - was Blotter, and Pu - $\boldsymbol{i}$ - was pumice. It reminded me of puzzles in the comics which I read as a very young child, but I found the exercise surprisingly difficult, while Gladys, the elderly lady I was paired with, was an absolute wizard at it, and guessed nearly all of them before I did.

Aqui mais uma vez o contexto e o efeito do texto se sobrepuseram ao significado das palavras: não houve preocupação de minha parte em fazer menção necessariamente a um urso, a uma lontra ou a ratinhos, uma vez que meu objetivo foi acima de tudo reproduzir em português o efeito suscitado pelo texto original. Mesmo assim, quando possível os animais citados no original serviram de ponto de partida, e assim passaram a constar no texto traduzido um urso, um gato e uma rata. Cabe salientar que o jogo permaneceu sem nome na tradução, uma vez que não encontrei menção a existência de uma brincadeira similar em português - muito embora a descrição clara das regras e os exemplos fornecidos por Desmond façam com que o trecho soe natural e verossímil apesar desta omissão:

Recebi um castigo merecido por esse atrevimento durante o exercício a seguir, que consistia em uma lista de palavras com letras faltando, sendo que as letras faltantes formavam o nome de um bicho. Assim, a solução de Conc - - - era Concurso, $\boldsymbol{R e}$ - - - era Regato e a $\boldsymbol{G}$ - - va - - era Gravata. Eu me lembrei dos quebra-cabeças nos gibis que eu lia quando era pequeno, mas achei o exercício muito difícil, enquanto Gladys, a senhora que estava resolvendo o exercício comigo, era craque na brincadeira e adivinhou quase todas as respostas antes de mim.

Durante o Natal, Desmond tem uma conversa com o neto Daniel que envolve um mal-entendido similar aos anteriores, que no entanto resulta em uma maior dificuldade de tradução devido não apenas ao contexto em que aparece, mas também à falta de um equivalente ao mesmo tempo cultural e linguístico para um dos termos que compõem o trocadilho: 
'So what did Father Christmas bring you, Dauphin Daniel?' I asked him, crouching down to bring myself to his level. 'Father Christmas bringed Daniel an icicle,' he said. 'An icicle? That doesn't sound like much of a present,' I said. 'A tricycle, Desmond,' Marcia said, and everybody around us laughed. One thing we deafies can do at a party is give people a few laughs with our mistakes, and I did not begrudge them this one. Daniel, however, didn't laugh, but turned his wide eyes on the grinning grown-up faces with a puzzled and faintly disapproving air. 'And it's "brought", not "bringed", Daniel,' his mother added. 'Father Christmas brought you a tricycle.'Being a teacher (though of maths not English), Marcia thinks it her duty to correct her children at every opportunity. Of course Daniel's mistake was perfectly logical and shows that he has already mastered the way to form the past tense of regular English verbs. You've got to grasp the rules before you learn the exceptions.

Uma vez que a ação se passa durante a época de Natal, durante o inverno na Europa, icicle não deixa de ter uma afinidade temática com a cena - porém este é um termo de tradução muito difícil para o português dada a inexistência quase total do fenômeno no Brasil. Segundo as definições encontradas em dicionários e glossários brasileiros, "carambina", "sincelo" e "caramelo" seriam as três opções disponíveis para traduzir o termo, mas descartei as duas primeiras porque imaginei que os termos seriam totalmente ignorados por uma parcela enorme de leitores e a última porque, em função da polissemia, remeteria em primeiro lugar à ideia de caramelo como um doce, e não como uma ponta de gelo. Às vezes o termo icicle é traduzido em obras de ficção pelo sintagma "estalactite de gelo", mas no trecho em questão essa solução também me pareceu demasiado extensa e técnica, e além do mais não permitia a recriação de nenhum mal-entendido plausível com a sonoridade palavra "triciclo" — este o presente efetivamente recebido por Daniel. Assim, a imagem da ponta de gelo não aparece na tradução, a menção explícita ao triciclo foi deslocada um pouco para diante e a confusão em português se deu entre as palavras "presente" e "pente". Graças a uma feliz coincidência entre as línguas, o erro cometido por Daniel quando conjuga um verbo irregular como se fosse regular deixa-se traduzir de maneira natural e verossímil em nosso idioma:

“O que o Papai Noel trouxe para você, Daniel Delfim?”, perguntei, agachandome para estar mais perto dele. "O Papai Noel trazeu um pente para Daniel”, disse ele. "Um pente? Que estranho", disse eu. "Um presente, Desmond", disse Marcia, e todos deram risada. Uma coisa que nós surdos podemos fazer é proporcionar boas risadas aos outros com os nossos mal-entendidos, e dessa vez. eu não me importei. Daniel, no entanto, não achou a menor graça e olhou para os rostos adultos que sorriam com um ar confuso e reprobatório. 'E é 'trouxe', 
não 'trazeu', Daniel", acrescentou a mãe dele. "O Papai Noel trouxe um presente para você. Um triciclo.” Como professora (embora de matemática), Marcia acha que tem o dever de corrigir os filhos dela em todas as ocasiões. Claro que o erro de Daniel foi muito lógico e mostra apenas que ele já sabe como conjugar os verbos regulares. Afinal, é preciso aprender as regras antes de aprender as exceções.

De volta ao grupo de leitura labial, Desmond novamente se junta a Gladys para uma das atividades propostas - e mais uma vez demonstra a intimidade que tem com o mundo das palavras:

Then we had a quiz on applications of the words Scot, Scotch, Scottish, which we had to try and answer by lip-speaking with a partner. I had Gladys as a partner again. I think she tries to sit next to me because she knows I'm welleducated and she's very competitive - so keen to be the first to complete the quiz that she often forgot to speak to me without voice. The clues were pretty easy: An egg encased in sausage meat. . . A famous explorer . . . A game played by children ... One that foxed everybody was A customary tax. I pretended I didn't know the answer: 'a scot'. Nothing to do with Scotland of course - it's Old English, now obsolete, though it survives in the expression 'scot-free'.

Nesse trecho, as diferentes acepções dos homofemas mencionados no início do parágrafo - que sugerem as respostas scotch egg, Robert Scott, hopscotch e scot-free (esta última a única mencionada explicitamente no livro) — não se prestam à recriação de uma jogo linguístico análogo em português. A última resposta torna a tarefa ainda mais complexa pela necessidade de se encontrar termos em português que sejam polissêmicos e além disso tenham uma acepção em geral ignorada, a não ser por um personagem que tenha uma excelente cultura no que diz respeito às palavras, como Desmond. Encontrei em português uma solução baseada nos homofemas "estágio" e “estádio", e mais uma vez reescrevi as pistas que poderiam levar à solução o comentário linguístico de Desmond de acordo com o novo contexto gerado por estes termos na minha tradução:

Fizemos mais uma atividade com os homofemas estágio e estádio, que tínhamos de tentar resolver falando uns com os outros só mexendo os lábios. Mais uma vez Gladys foi a minha parceira. Acho que ela gosta de sentar perto de mim porque sabe que sou bem-educado e ela é muito competitiva - tão competitiva, na verdade, que muitas vezes esqueceu de falar comigo sem voz. As pistas eram bem fáceis: Lugar onde se assiste a uma partida esportiva... Fase de um processo... Treinamento oferecido a profissionais com pouca experiência... Uma que deixou todo mundo perplexo foi Uma medida de comprimento. Eu 
fingi não saber que a resposta era "estádio". Nada a ver com os jogadores de futebol, é claro - mas o estádio era uma medida usada pelos antigos gregos, que equivale a mais ou menos duzentos metros.

Já no final do livro, Desmond reflete sobre tudo aquilo pelo que passou e faz menção explícita aos trocadilhos feitos com os termos deaf e death:

\begin{abstract}
'Deafness is comic, blindness is tragic,' I wrote earlier in this journal, and I have played variations on the phonetic near-equivalence of 'deaf' and 'death', but now it seems more meaningful to say that deafness is comic and death is tragic, because final, inevitable, and inscrutable. As Wittgenstein said, 'Death is not an event in life.' You cannot experience it, you can only behold it happening to others, with various degrees of pity and fear, knowing that one day it will happen to you.
\end{abstract}

Aqui a principal dificuldade surgiu como resultado da própria estratégia tradutória adotada em relação aos termos: enquanto no original os trocadilhos são feitos sempre com um único par de termos, na tradução os diferentes contextos em que aparecem tornaram essa repetição impossível - e por este motivo adotei diferentes soluções em diferentes momentos, como venho ilustrando ao longo deste artigo. No entanto, a menção explícita à morte - tema central do trecho acima - torna-se necessária na tradução deste trecho, embora a palavra "morte" não apareça praticamente nenhuma vez nos trocadilhos em português recriados no texto da tradução, sendo a única exceção o pastiche do poema de Macaulay discutido anteriormente. A solução que adotei consistiu manter a referência ao trocadilho entre "maldição" e "má audição" e em usar este trocadilho para retomar o poema de Macaulay e a menção à morte, que assim pode figurar também na tradução como tema central do trecho e mote para a citação de Wittgenstein:

Em alguma parte deste diário eu escrevi que "A surdez é cômica, a cegueira é trágica", e fiz vários trocadilhos com a equivalência fonética quase perfeita entre "má audição" $e$ "maldição", chegando até a citar a "maldição da morte" de Macaulay; mas agora parece mais adequado dizer que a surdez é cômica e a morte é trágica, porque ela é inevitável, definitiva e inescrutável. Como Wittgenstein disse, "A morte não é um evento da vida". Nós jamais a experimentamos - só podemos observar quando ela chega para os outros, sentindo compaixão e medo em intensidades diversas e sabendo que um dia ela também chegará para nós.

Depois de realizado todo esse trabalho, faltava ainda dar um nome à tradução. 
Uma vez que a constância do trocadilho entre deaf e death não se manteve no texto em portuguê, tampouco me não pareceu necessário mantê-lo no título, e assim estabeleci como objetivo encontrar um título que fizesse uma brincadeira ou trocadilho com uma expressão cristalizada da língua e fizesse alusão à surdez — um problema que considero ter resolvido com o título Surdo mundo, que ademais me parece uma descrição bastante fidedigna de todo o universo em que a história se passa.

\section{Bibliografia}

CAMPOS, Haroldo de. Da tradução como criação e como crítica. In:

Metalinguagem. São Paulo: Cultrix, 1976. p.21-38.

LODGE, David. Deaf Sentence. Londres: Harvill Secker, 2008.

Surdo mundo. Porto Alegre: L\&PM, 2010.

REISS, Katharina; VERMEER, Hans J. Grundlegung einer allgemeine Translationstheorie. Tübingen: Max Niemeyer, 1991.

VERMEER, Hans J. Skopos and Commission in Translational Action. Trad. Andrew Chesterman. In: VENUTI, Lawrence. The Translation Studies Reader. London/New York: Routledge, 2004. p. 221-232. 